\title{
Perceptual load modulates the processing of distractors presented at task-irrelevant locations during the attentional blink
}

\author{
James C. Elliott and Barry Giesbrecht \\ University of California, Santa Barbara, California
}

\begin{abstract}
The distribution of attention in both space and time is critical for processing our dynamic environment. Studies of spatial attention suggest that the distribution of attention is decreased when the perceptual load of a task increases, resulting in decreased processing of task-irrelevant distractors. Studies of the attentional blink (AB) suggest that the temporal distribution of attention also influences distractor processing, such that distractor processing increases during the $\mathrm{AB}$ relative to outside the $\mathrm{AB}$ (Jiang \& Chun, 2001). Two experiments are reported in which the extent to which the difficulty of the first target task (T1) modulates the processing of task-irrelevant distractors during the $\mathrm{AB}$ was tested. To investigate this issue, both the first and second target tasks (T1 and T2) required identifying a central stimulus that was flanked by low-load or high-load distractors. Consistent with previous studies of the $\mathrm{AB}$, there was evidence of more distractor processing during the $\mathrm{AB}$ than outside the $\mathrm{AB}$. Critically, however, the interference caused by distractors presented simultaneously with $\mathrm{T} 2$ during the $\mathrm{AB}$ was reduced when T1 perceptual load was high relative to when it was low. These results suggest that increasing T1 perceptual load decreases distractor processing during the $\mathrm{AB}$ and that perceptual processes influence both the temporal and spatial distribution of attention.
\end{abstract}

Survival in a complex and dynamic environment requires the ability to selectively attend to task-relevant information while ignoring distracting task-irrelevant information. Although people are effective at maintaining attention to specific tasks, disruptions of selective attention commonly occur. Laboratory studies suggest that the efficacy of selective attention is modulated by the structure of a task and the demands that it places on perceptual and cognitive systems (Lavie, 2005; Pashler, 1998; Vogel, Woodman, \& Luck, 2005; Yantis \& Johnston, 1990). For instance, increasing the difficulty of a task by increasing the visual similarity between a target and the surrounding distractors can lead to reduced behavioral interference and neuronal responses evoked by task-irrelevant distractors, indicating an increase in the selectivity of attention (Handy \& Mangun, 2000; Handy, Soltani, \& Mangun, 2001; Lavie, 1995; Lavie, Hirst, de Fockert, \& Viding, 2004). Other studies indicate that the reduced influence of task-irrelevant distractors that occurs with increased perceptual similarity is not due to generalized increases in task difficulty, because increasing the difficulty of a task by requiring participants to hold more information in working memory can lead to increased behavioral interference and increased neural activity evoked by task-irrelevant distractors, indicating a decrease in the selectivity of attention (de Fockert, Rees, Frith, \& Lavie, 2001; Lavie et al., 2004). Thus, depending on the structure of the task and the demands placed on different perceptual and cognitive systems, the selectivity of attention can be increased or decreased.

Changes in the selectivity of attention that occur with task demands have been explained by several models that propose multiple selective attention mechanisms that operate at different stages of processing (Lavie, 2005; Pashler, 1998; Vogel, Luck, \& Shapiro, 1998; Vogel et al., 2005; Yantis \& Johnston, 1990). For instance, according to one of these models, commonly known as the load theory of selective attention (Lavie, 2005; Lavie et al., 2004; Lavie \& Tsal, 1994), information processing is performed by two resource-limited stages. The first stage consists of the perceptual processing system; the second stage is composed of the cognitive control system. At the perceptual stage, resources are allocated automatically and exhaustively, with priority given to processing information that is consistent with the current task set (i.e., task-relevant information). Within this scheme, when the perceptual processing required to identify the task-relevant information requires all available resources (i.e., high load), no spare capacity is available for perceptual processing of task-irrelevant information; therefore, the likelihood that extraneous information will interfere with performance is reduced. In contrast, under low-load conditions, resources not required for processing task-relevant information spill over to the perceptual processing of task-irrelevant infor-

J. C. Elliott, elliott@psych.ucsb.edu 
mation, increasing the likelihood that the information will interfere with performance. In other words, the load placed on the perceptual system by processing task-relevant information determines the extent to which irrelevant information is processed. The cognitive control stage of this model is responsible for, among other things, inhibiting interference from distracting information that is processed at the first stage from influencing subsequent behavior (i.e., in cases of low perceptual load). If the demands on this stage are increased by, for example, increasing working memory load, not enough resources are available to inhibit the processing of the task-irrelevant information. Therefore, unlike the effect of increased load at the perceptual stage, increased load at the cognitive control stage results in an increase in the interfering effects of taskirrelevant information.

Although the load theory of selective attention provides a useful framework for understanding the conditions that modulate the selectivity of attention, it is almost exclusively based on studies in which the distribution of attention over space was measured. However, selective attention also has a particular temporal distribution. For instance, one common approach is to use a dual-task paradigm in which two masked targets are presented in rapid succession at the same location. Correct identification of the first target (T1) leads to impaired identification of the second target (T2). This impairment in conscious report of $\mathrm{T} 2$, known as the attentional blink (AB; Raymond, Shapiro, \& Arnell, 1992), lasts for about $500 \mathrm{msec}$, and it is generally thought to reflect the cost of selectively attending to T1. One of the most consistent theoretical claims about the $\mathrm{AB}$ is that it reflects a failure at a relatively late stage of information processing (Chun \& Potter, 1995; Olivers \& Meeter, 2008; Vogel et al., 1998).

Importantly, recent models of the $\mathrm{AB}$ claim that some of the late-stage processes that are involved include cognitive control processes that are responsible for inhibiting distracting information (Olivers \& Meeter, 2008). When the claim that cognitive control mechanisms are taxed during the $\mathrm{AB}$ is considered in conjunction with the load theory notion that cognitive control mechanisms are required to inhibit task-irrelevant information, the emergent implication is that task-irrelevant information should be processed more extensively during the $\mathrm{AB}$ than it would outside the $\mathrm{AB}$. Consistent with this prediction, Jiang and Chun (2001) reported more interference from taskirrelevant distractors presented simultaneously with $\mathrm{T} 2$ during the $\mathrm{AB}$ than outside the $\mathrm{AB}$. In other words, the increase in distractor interference during the $\mathrm{AB}$ suggests that the efficacy of selective attention decreased during the AB.

Although there are numerous demonstrations that taskirrelevant or otherwise unattended information is processed during the $\mathrm{AB}$, consistent with the idea that the $\mathrm{AB}$ represents a failure at the cognitive control stage, recent work suggests that there may also be a role for perceptual limitations. For example, in a series of event-related potential (ERP) studies, Jolicœur and colleagues measured the N2pc ERP component evoked by a T2 presented in the periphery along with simultaneously presented dis- tractors (Dell'Acqua, Sessa, Jolicœur, \& Robitaille, 2006; Jolicœur, Sessa, Dell'Acqua, \& Robitaille, 2006a, 2006b). These investigators found that the N2pc was completely suppressed during the AB. Because the N2pc is thought to reflect processes involved in the allocation of perceptual processing resources to facilitate selection of a target from among distractors (e.g., Eimer, 1996; Luck \& Hillyard, 1994), the attenuation of the N2pc component during the $\mathrm{AB}$ suggests that the ability to allocate spatial attention during the $\mathrm{AB}$ is diminished. Other recent studies have shown that increasing the perceptual load of the T1 task reduces the extent to which the context-sensitive N400 ERP component evoked by $\mathrm{T} 2$ and the extent to which $\mathrm{T} 2$ stimuli that are personal names survive the $\mathrm{AB}$ (Giesbrecht, Sy, \& Elliott, 2007; Giesbrecht, Sy, \& Lewis, 2009). On the basis of these results, Giesbrecht et al. (2007, 2009) proposed that the finding that $\mathrm{T} 1$ load affects whether T2 is processed to a perceptual or postperceptual level during the $\mathrm{AB}$ suggests that perceptual load also modulates the distribution of attention over time. In the present work, the proposal that $\mathrm{T} 1$ perceptual load modulates postperceptual processing during the $\mathrm{AB}$ will be referred to as the load hypothesis.

Whereas the results of Giesbrecht et al. (2007) and others are consistent with the notion that increasing task demands influence the extent to which task-relevant information is processed during the $\mathrm{AB}$, the present experiments were designed in order to determine the influence that increasing T1 load has on the processing of task-irrelevant spatial distractors presented with $\mathrm{T} 2$. Load theory suggests that if there is an increase in the perceptual demand on the T1, there should be fewer perceptual resources available to spill over to the distractors surrounding the T2. Thus, on the basis of load theory, spatially presented distractors should have less of an influence on T2 processing when the T1 task is high in perceptual load than when the T1 task is low in perceptual load. In order to test this prediction, distractor similarity was manipulated on both T1 and T2 in two experiments. The purpose of Experiment 1 was to examine the influence of manipulating T1 load on the processing of the distractors presented simultaneously with T2. According to load theory and recent studies of the AB (Giesbrecht et al., 2007; Giesbrecht et al., 2009), when T1 is surrounded by perceptually demanding distractors, there should be a decrease in the influence of distractors on the accuracy of 22 identification during the $\mathrm{AB}$ relative to when the load of the T1 task is low. Importantly, this experiment will allow us to test this novel prediction, while at the same time allowing us to replicate previous studies by directly comparing the amount of distractor interference during the $\mathrm{AB}$ with that to outside the $\mathrm{AB}$ (Jiang \& Chun, 2001).

\section{EXPERIMENT 1}

In Experiment 1, both T1 and T2 were arrows $(<$ or $>)$ presented centrally, and the task in each case was to indicate the direction the arrow was pointing. To measure the $\mathrm{AB}$, the temporal lag between $\mathrm{T} 1$ and $\mathrm{T} 2$ was manipulated to be 320,400 , or $1,100 \mathrm{msec}$ (approximately lags 3, 4, 
and 11 in an RSVP task). To measure the influence of task load, arrows that were either congruent $(<<<<<)$ or incongruent $(>><>>)$ were presented simultaneously with the centrally presented target stimuli. According to load theory, changes in perceptual load occur with changes in the number of items that need to be identified, the number of perceptual operations that are required, and when perceptual identification is more demanding on attention (Lavie, 2005). Because of the long line of studies demonstrating changes in performance (both accuracy and response time) as a function of the congruency between peripherally presented distractors and a central target (Eriksen \& Eriksen, 1974; Giesbrecht et al., 2007), the present study is an example of when perceptual identification is more demanding on attention. We will refer to the incongruent and congruent distractor conditions as the high- and low-load conditions, respectively (Giesbrecht et al., 2007). There were three key predictions. First, in line with previous studies, high T1 load should decrease accuracy on T2. Second, to the extent that the AB reflects an impairment of cognitive control, under conditions of low load there should be more influence of the distractors during the $\mathrm{AB}$ than outside the $\mathrm{AB}$. Finally, and most critically, if there is a contribution of perceptual load to the spatial distribution of attention during the $\mathrm{AB}$, the influence of the distractors presented with $\mathrm{T} 2$ should decrease under conditions of high $\mathrm{T} 1$ load within the $\mathrm{AB}$.

\section{Method}

Participants. Thirty undergraduates from the University of California, Santa Barbara received class credit for participating in this study (mean age $=18.39$ years; 21 were female, and 27 were righthanded). Two participants were excluded because of low T1 accuracy $(0 \%$ in one or more conditions).

Apparatus and Stimuli. Stimulus presentation was implemented with custom scripts that utilized the Psychophysics Toolbox (Brainard, 1997). The targets, distractors, and masks were uppercase black letters, numbers, and symbols presented on a gray screen in 40-pt. Arial font. Target displays consisted of a single centrally presented target arrow $(<$ or $>$ ) that was flanked by two distractors on each side $(<<$ or $>>)$. The T1 and T2 target together with their respective distractors subtended $0.52^{\circ} \times 2.08^{\circ}$. The stimuli were presented on a color CRT monitor positioned $110 \mathrm{~cm}$ from the participants.

Procedure. Each trial started with a fixation cross, which remained on the screen until the stimulus sequence was initiated by the participants' pressing the space bar on the keyboard. Once the trial was initiated, there was a random blank interval that ranged between 500 and $1,000 \mathrm{msec}$, followed by the target displays. The first target was presented for $80 \mathrm{msec}$, followed by a 20 -msec blank interstimulus interval (ISI), and then a mask $(80 \mathrm{msec})$. After the specified temporal lag had elapsed (see the Design section), the second target was presented $(80 \mathrm{msec})$, followed by a blank ISI $(20 \mathrm{msec})$ and a mask $(80 \mathrm{msec})$. The masks were different for each target and for each trial and consisted of randomly selected numbers and letters (seven for T1 and five for T2). After the second target was presented, there was a random interval of 500-1,000 msec, followed by response probes for each target task. The task for both targets was to indicate the direction of the central arrow as accurately as possible, with no emphasis on response time. A sample trial sequence is illustrated in Figure 1.

Design. Three within-subjects variables were manipulated. One variable was the temporal lag between the targets. This variable permits one to measure the performance impairment on the second target as a function of the temporal separation between the two targets (i.e., the $\mathrm{AB}$ ). Three $\mathrm{T} 1-\mathrm{T} 2$ lags were used, two were inside the typical $\mathrm{AB}$ time window ( 320 and $400 \mathrm{msec}$ ), the third was outside the typical $\mathrm{AB}$ window and served as an optimal performance control $(1,100 \mathrm{msec})$. The second and third variables were the targetdistractor relationship for the first and second targets, respectively. In each case, the targets were flanked by distractors that were either congruent $(<<<<<)$ or incongruent $(<<><<)$. There were four possible combinations of T1 load and T2 load for each temporal lag: low T1 load and low T2 load, low T1 load and high T2 load, high T1 load and low T2 load, and high T1 load and high T2 load. All variables were factorially combined and randomly intermixed within a session, and there were a total of 480 trials ( 40 trials per condition) divided into five blocks of trials.

\section{Results}

The overall mean proportion of correct $\mathrm{T} 1$ responses was .75. As was expected, there was a main effect of $\mathrm{T} 1$ load on the T1 proportion correct (low T1 load, $M=.89$; high T1 load, $M=.62)\left[F(1,29)=53.01, M S_{\mathrm{e}}=0.121, p<\right.$ $.001]$. There was also a small but significant main effect of lag (mean accuracy, $320 \mathrm{msec}=0.73,400 \mathrm{msec}=0.752$, $1,100 \mathrm{msec}=0.773)\left[F(2,58)=12.67, M S_{\mathrm{e}}=0.003\right.$, $p<.001]$. There were no significant interactions. Importantly, the main effect of T1 load confirms that the high T1 load condition was more difficult than the low T1 load condition.

The analyses of the T2 task were based on trials on which the participants accurately reported $\mathrm{T} 1$ (i.e., $\mathrm{T} 2 \mid \mathrm{T} 1)$. Mean proportion correct T2 $\mid \mathrm{T} 1$ responses are shown as a function of T1 load, T2 load, and lag in Figure 2. There was an overall effect of lag, such that accuracy was impaired at short lags relative to long lags $\left[F(2,58)=25.73, M S_{\mathrm{e}}=0.016, p<.001\right]$. There were also main effects of both T1 load and T2 load, such that overall accuracy was lower when target load was high [low T1 load, $M=.70$; high T1 load, $M=.66 ; F(1,29)=$ $17.49, M S_{\mathrm{e}}=0.008, p<.001$ ] [low T2 load, $M=.80$; high T2 load, $M=.56 ; F(1,29)=92.86, M S_{\mathrm{e}}=0.057$, $p<.001]$. Critically, there was both an interaction between T1 load and T2 load $\left[F(1,29)=50.95, M S_{\mathrm{e}}=\right.$ $0.018, p<.001]$ and an interaction among T1 load,

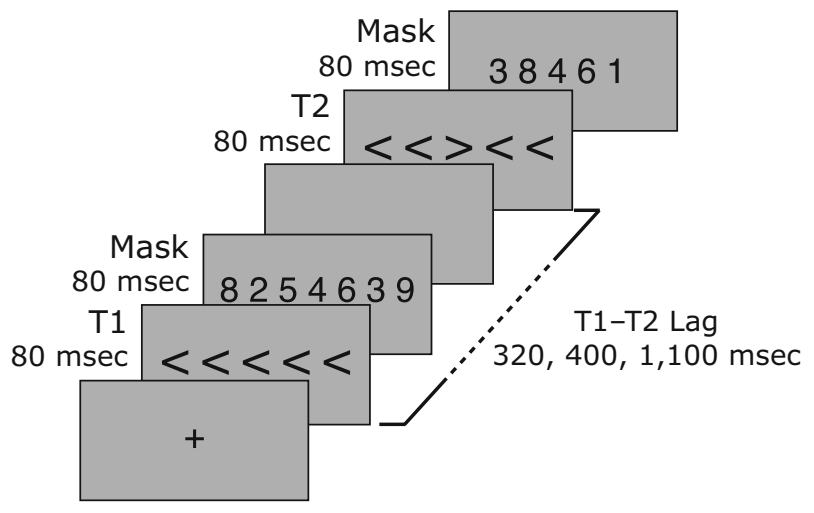

Figure 1. Representation of the trial structure and target types used for Experiment 1. T1 is an example of high T1 load, and T2 is an example of low T2 load. Both T1 and T2 could be either high or low load. 
T2 load, and lag $\left[F(2,58)=4.36, M S_{\mathrm{e}}=0.012, p<\right.$ $.02]$. The two-way interaction was such that the effect of T2 load was smaller when T1 load was high than when T1 load was low. The three-way interaction was such that the reduction of the effect of T2 load observed when T1 load was high was larger at the short lags than at the long lags.

To examine the effect of T1 load on T2 distractor processing during the AB (i.e., the influence of T1 load on $\mathrm{T} 2$ distractor processing in the $\mathrm{T} 1$ load $\times \mathrm{T} 2 \mathrm{load} \times$ lag interaction) and to more directly test our hypothesis, distractor interference scores were calculated for each participant by subtracting the proportion correct in the high T2 load condition from that in the low T2 load condition for each lag. ${ }^{1}$ The resulting distractor interference scores are shown in Figure 3 as a function of T1 load and lag. There are two key findings. First, under conditions of low T1 load, there was more distractor interference during the AB than outside the AB [320 vs. 1,100 msec; $\left.t(29)=2.92, p<.01, S E M_{\mathrm{D}}=0.039\right]$. Second, during the $\mathrm{AB}$, the effect of distractor interference in the high T1 load condition was significantly smaller than that in the low T1 load condition [high T1 load, $M=.14$; low $\mathrm{T} 1$ load, $M=.40 ; t(29)=-5.239, p<.001, S E M=$ $0.0485]$.

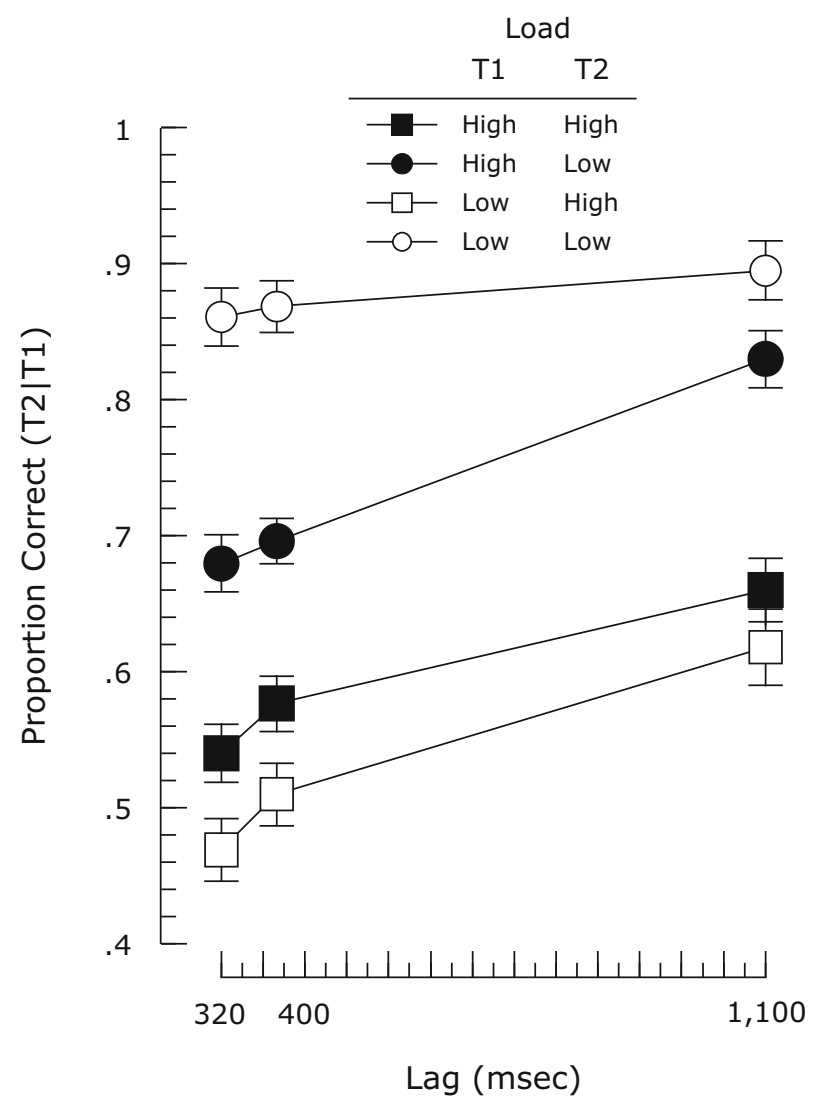

Figure 2. Mean proportion correct T2 responses given accurate report of T1 (T2|T1) for Experiment 1. Error bars in this and subsequent figures represent one standard error of the mean computed in a manner appropriate for within-subjects designs (Loftus \& Masson, 1994).

\section{Discussion}

There were two key results from Experiment 1. First, under conditions of low T1 load, there was more distractor interference during the $\mathrm{AB}$ than outside the $\mathrm{AB}$. This finding replicates the results of Jiang and Chun (2001), who also reported increased distractor interference during the $\mathrm{AB}$ relative to outside the $\mathrm{AB}$. Second, the amount of distractor interference during the $\mathrm{AB}$ was smaller when $\mathrm{T} 1$ load was high relative to when $\mathrm{T} 1$ load was low. The finding of increased distractor interference during the $\mathrm{AB}$ relative to outside the $\mathrm{AB}$ is consistent with the notion that functioning of key attentional control mechanisms is impaired during the AB (Jiang \& Chun, 2001). However, the reduction in distractor interference during the typical $\mathrm{AB}$ window as a function of load suggests that there is an additional mechanism at play. We propose that this additional mechanism is perceptual and that its capacity and/ or the manner in which its resources are allocated to space, time, and other potential selection features (e.g., objects, color, form, motion) can influence processing during the AB. In other words, these results suggest that the first stages of perceptual processing proposed by all models of the AB should not be considered to be free of capacity limits. That is, there are two sources that can influence the processing of information during the $\mathrm{AB}$ : One of these is perceptual, and the other is postperceptual.

Although this proposal is consistent with recent studies in the literature (Dell'Acqua et al., 2006; Giesbrecht et al., 2007; Giesbrecht et al., 2009; Jolicœur et al., 2006a, 2006b; Vachon, Tremblay, \& Jones, 2007), two issues must be addressed. First, it could be argued that the reduction in distractor interference observed here is simply an artifact of the high level of performance in the low T1 load condition and that increasing T1 load simply pushed performance lower in all conditions. Certainly, there was a reduction in performance with increased load when the T1-low/T2-low and the T1-high/T2-low conditions are compared. However, this relative reduction was not observed in all conditions of high T1 load. Indeed, when T2 load was also high, there was an improvement in performance when T1 load was increased. In fact, performance was significantly higher during the $\mathrm{AB}$ in the high T1 load condition (low T1 load, $M=.47$; high T1 load, $M=.54)\left[t(29)=2.53, p>.02, S E M_{\mathrm{D}}=0.028\right]$. This reduction in distractor interference under conditions of high load is consistent with the prediction that increased T1 load reduces the amount of perceptual resources available to process the task-irrelevant distractors.

The second issue that must be addressed pertains to the source of the effect of load. Specifically, because the distractors used in Experiment 1 were visually similar to the targets and were mapped onto a competing response, it is unclear whether the reduction in distractor interference is due to changes in perceptual load, response conflict, or some combination of the two. Although the unspeeded posttrial responses used in this task likely minimized the influence of response conflict, it is still possible that some, if not all, of the effect observed could be due to residual response conflict. Experiment 2 was designed to address this issue. 


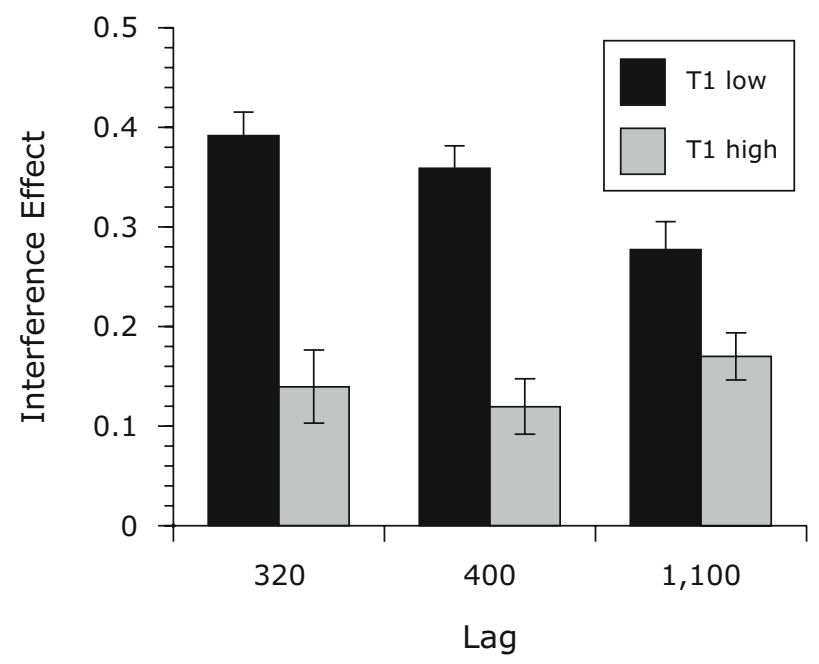

Figure 3. Mean distractor interference scores for Experiment 1. Distractor interference scores were computed for each participant by subtracting $p(\mathrm{~T} 2 \mid \mathrm{T} 1)$ in the high T2 load condition from the $p(\mathrm{~T} 2 \mid \mathrm{T} 1)$ low-load condition for each lag and T1 load condition.

\section{EXPERIMENT 2}

In order to isolate the source of load and thereby provide more clarity on the cause of the reduction in the distractor interference observed in Experiment 1, the target and distractor stimuli were modified to remove response competition while maintaining some degree of visual similarity. Specifically, in Experiment 2, we employed another common manipulation of load in which the stimuli were selected so that high-load distractors shared perceptual similarities with the targets, and low-load distractors did not (Beck \& Lavie, 2005; Eriksen \& Eriksen, 1974). Critically, neither set of distractors mapped onto potential response; therefore, any reductions in the distractor interference observed during the $\mathrm{AB}$ cannot be explained by increases in load caused by response conflict.

\section{Method}

Participants. Thirty-four University of California, Santa Barbara undergraduates participated for course credit (mean age $=$ 19.06 years; 23 were female, and 30 were right-handed). One participant was excluded because of chance performance on the T1 task.

Apparatus and Stimuli. There were two changes to the stimuli from Experiment 1. First, the targets and distractors consisted of uppercase letters rather than arrows. Second, both the T1 and T2 masks consisted of sets of five numbers selected randomly for each target and trial.

Procedure. The procedure was the same as that in Experiment 1, except that the task for both targets was to discriminate whether the centrally presented letter was an X or an N. A sample trial sequence is shown in Figure 4.

Design. The design was the same as that in Experiment 1. The only change was that the manipulation of load was achieved by selecting the distractor letters on the basis of their visual similarity to the target letters ( $\mathrm{X}$ or $\mathrm{N}$ ) and ensuring that they did not map onto a competing response. The low-load set (CODQ) shared fewer perceptual features with the target than did the high-load set (YVKZ).

\section{Results and Discussion}

A within-subjects repeated measures analysis of $\mathrm{T} 1$ accuracy with three factors (T1 load, T2 load, and lag) revealed main effects of T1 load (low T1 load, $M=.94$; high T1 load, $M=.87)\left[F(1,32)=49.79, M S_{\mathrm{e}}=0.008\right.$, $p<.001]$ and lag (320 msec, $M=.89 ; 400 \mathrm{msec}, M=$ $.90 ; 1,100 \mathrm{msec}, M=.91)\left[F(2,64)=6.89, M S_{\mathrm{e}}=0.003\right.$, $p<.01]$. Additionally, there was a significant T1 load $\times$ T2 load interaction $\left[F(1,32)=4.26, M S_{\mathrm{e}}=0.002, p<\right.$ $.05]$, such that when T1 load was low, the proportion correct was 0.012 higher when T2 load was also low (low T2 load, $M=.942$; high T2 load, $M=.93$ ), but when T1 load was high, it was .012 higher when T2 load was also high (low T2 load, $M=.868$; high T2 load, $M=$ .876).

Mean proportion correct T2 $\mid \mathrm{T} 1$ is plotted in Figure 5 as a function of T1 load, T2 load, and lag. Overall performance was lower when T1 load was high than when it was low (low T1 load, $M=.88$; high T1 load, $M=.86$ ) $\left[F(1,32)=8.77, M S_{\mathrm{e}}=0.005, p<.01\right]$, when T2 load was high than when it was low (low T2 load, $M=.91$, high T2 load, $M=.82)\left[F(1,32)=72.03, M S_{\mathrm{e}}=0.01\right.$, $p<.001]$, and at short lags than at long lags (320 msec, $M=.82 ; 400 \mathrm{msec}, M=.85 ; 1,100 \mathrm{msec}, M=.92)$ $\left[F(2,64)=41.72, M S_{\mathrm{e}}=0.007, p<.001\right]$. In addition to these main effects, there were two key interactions. First, there was an interaction between T2 load and lag $\left[F(2,64)=4.66, M S_{\mathrm{e}}=0.005, p<.05\right]$. Visual inspection of Figure 5 suggests that this interaction was driven by a larger effect of $\mathrm{T} 2$ load during the $\mathrm{AB}$ than outside the $A B$. Second, there was a significant three-way interaction among T1 load, T2 load, and lag $\left[F(2,64)=3.28, M S_{\mathrm{e}}=\right.$ $0.004, p<.05]$.

To once again isolate the influence of T1 load on $\mathrm{T} 2$ distractor processing in the three-way interaction among T1 load, T2 load, and lag, the distractor interference effect was calculated as in Experiment 1, and the resulting scores are shown in Figure 6. There were two key findings. First, under conditions of low T1 load, there

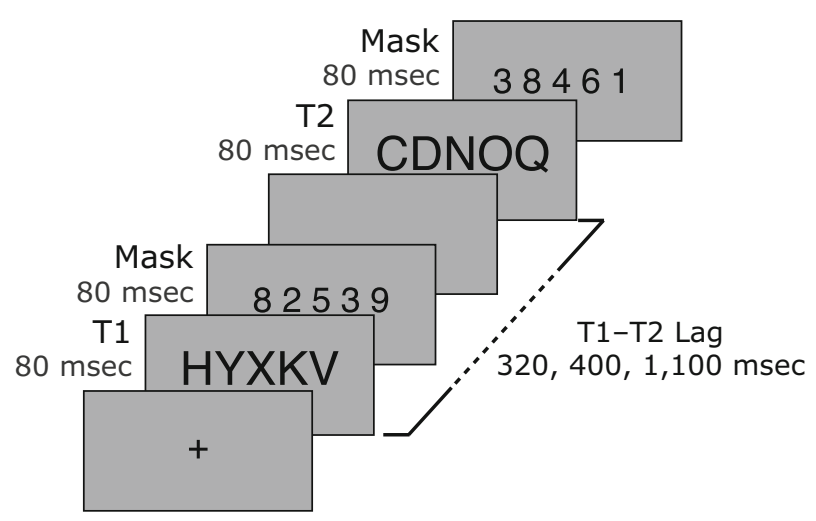

Figure 4. Representation of the trial structure and target types used for Experiment 2. T1 is an example of high T1 load, and T2 is an example of low T2 load. Both T1 and T2 could be either high or low load. 


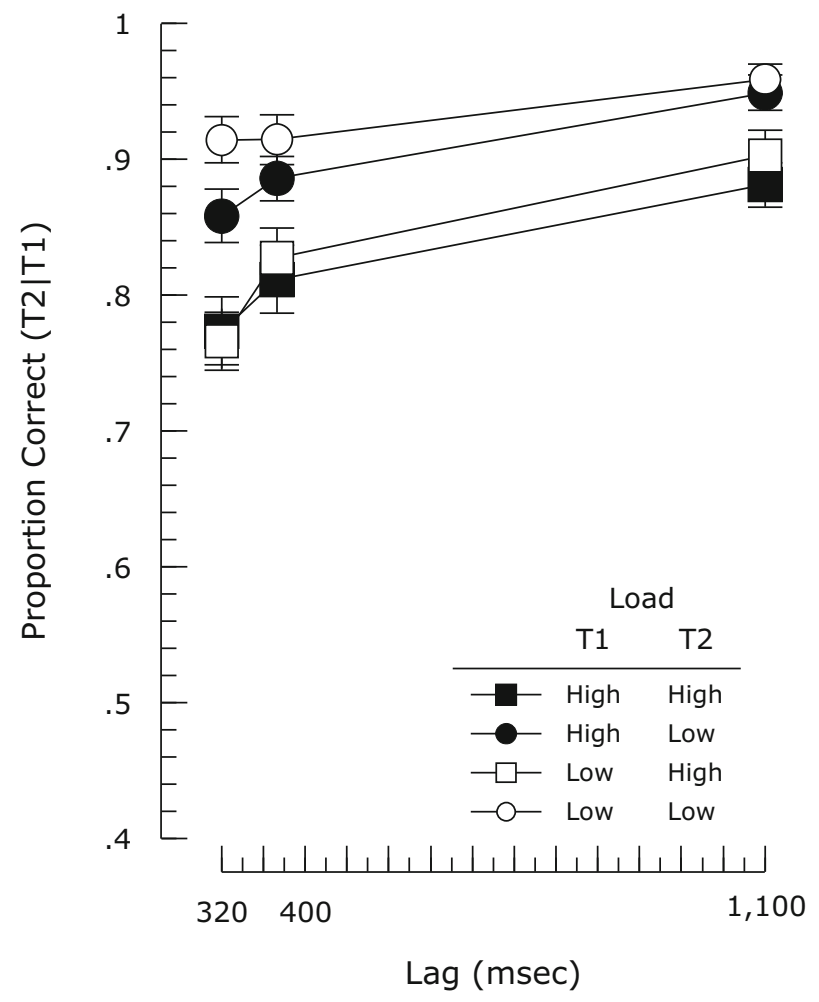

Figure 5. Mean proportion correct $\mathrm{T} 2$ responses given accurate report of T1 (T2|T1) for Experiment 2.

was more distractor interference during the $\mathrm{AB}$ than outside the $\mathrm{AB}(320 \mathrm{msec}, M=.14 ; 1,100 \mathrm{msec}, M=.06)$ $\left[t(33)=4.45, p<.001, S E M_{\mathrm{D}}=0.02\right]$. This result replicates the results of Experiment 1 and those of Jiang and Chun (2001), indicating that under some conditions processing of task-irrelevant information may increase during the $\mathrm{AB}$ relative to outside the $\mathrm{AB}$. Second, and most critically for the present purposes, there was more distractor interference during the $\mathrm{AB}$ when $\mathrm{T} 1$ load was low than when T1 load was high (low T1 load, $M=.14$; high T1 load, $M=.07)\left[t(33)=3.15, p<.01, S E M_{\mathrm{D}}=0.02\right]$. Interestingly, both of these results were observed despite an overall higher level of performance and overall smaller interference scores relative to those in Experiment 1. The overall improvement is likely due to the removal of response conflict induced by the distractors. Despite the source of differences in accuracy, this demonstrates that the present findings are not simply an artifact of overall difficulty of the task, but rather, they appear to be tied directly to the manipulation of load on the T1 task. The results of Experiment 2 demonstrate that the reduction in the influence of task-irrelevant distractors during the $\mathrm{AB}$ observed in Experiment 1 was not solely due to the response conflict engendered by the task-irrelevant flankers but, rather, that the interference caused by the perceptual similarity between the target and distractors is sufficient to modulate the processing of task-irrelevant information during the $\mathrm{AB}$.

\section{GENERAL DISCUSSION}

The purpose of the present work was to investigate the extent to which $\mathrm{T} 1$ load modulates the processing of taskirrelevant information presented during the AB. Two experiments were presented in which task-irrelevant information processing was indexed by measuring the amount of behavioral interference caused by distractors presented simultaneously with T2. The results of Experiment 1 demonstrated that the amount of distractor interference within the $\mathrm{AB}$ can be reduced under conditions of high $\mathrm{T} 1$ load relative to low $\mathrm{T} 1$ load, while replicating previous studies showing that the amount of distractor interference is larger during the $\mathrm{AB}$ than outside the $\mathrm{AB}$ (Jiang \& Chun, 2001). The results of Experiment 2 replicated the results of Experiment 1 with task-irrelevant distractors that did not map onto a competing response. Together, these results support the hypothesis that task demands imposed by the T1 task can modulate the selectivity of attention to task-irrelevant information during the AB.

In addition to providing strong support for the hypothesis that the perceptual demands imposed by T1 limit processing of task-irrelevant spatial distractors during the $\mathrm{AB}$, the present results also dovetail with recent studies showing that both perceptual and postperceptual stages of $\mathrm{T} 2$ processing can also be constrained during the $\mathrm{AB}$. At the perceptual stage, Jolicœur and colleagues (Dell'Acqua et al., 2006; Jolicour et al., 2006a, 2006b) found that the N2pc ERP component evoked by a T2 presented in the periphery along with simultaneously presented distractors was completely suppressed during the AB. Critically, because the N2pc ERP component is thought to reflect early-stage processes involved in the allocation of perceptual processing resources to facilitate selection of a target from among distractors (e.g., Eimer, 1996; Luck \& Hillyard, 1994; Woodman \& Luck, 1999), the finding

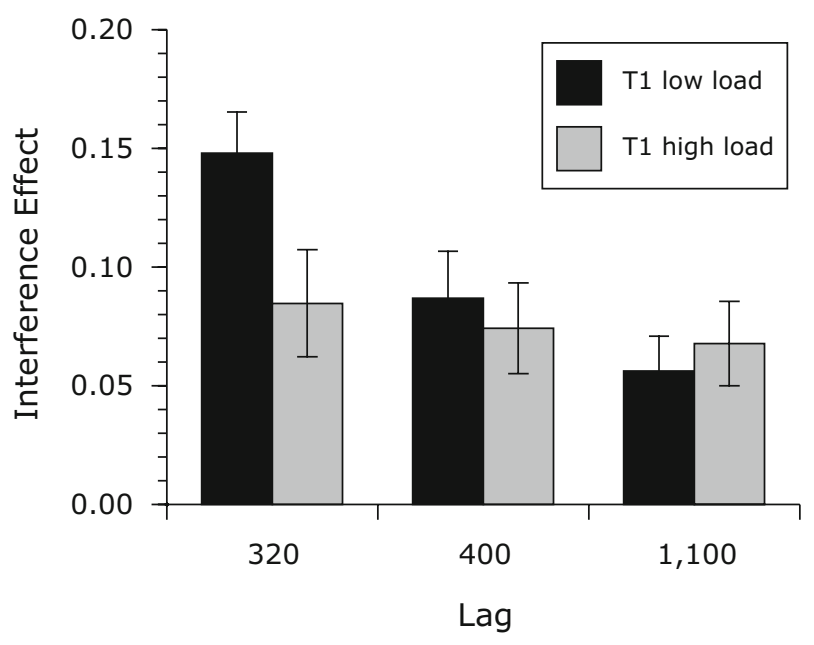

Figure 6. Mean distractor interference scores for Experiment 2, computed in the same manner as in Experiment 1. Note that because of the overall higher performance in Experiment 2 than in Experiment 1, the scale of the $y$-axis covers a different range than in Figure 3 (see the text). 
of a suppressed $\mathrm{N} 2 \mathrm{pc}$ during the $\mathrm{AB}$ suggests that under some conditions perceptual processing is compromised during the $\mathrm{AB}$. There are several recent reports indicating that at the postperceptual stage, increasing T1 perceptual load leads to reductions in the magnitude of the contextsensitive N400 ERP component (Giesbrecht et al., 2007), switches of task set reduce semantic processing of T2 (Vachon et al., 2007), and increasing T1 load reduces the extent to which personal names survive the $\mathrm{AB}$ (Giesbrecht et al., 2009). Although the present findings converge with these previous reports, they are also unique, because they show that T1 load influences the extent to which task-irrelevant information is processed. More specifically, in some of the studies reviewed above, the extent to which processing of the task-relevant second target was modulated by changes in T1 load was measured (e.g., Giesbrecht et al., 2007; Giesbrecht et al., 2009). In contrast, the present study tested the influence of perceptual load on task-irrelevant distractor processing during the AB. Given that high perceptual load on T1 significantly decreased distractor interference on high-load T2 trials during the $\mathrm{AB}$, the present study, combined with the previous experiments, demonstrates that perceptual load can modulate both task-irrelevant distractor and task-relevant target processing during the $\mathrm{AB}$.

The present work also converges with studies in the broader attention literature showing that increased perceptual load modulates the spatial distribution of selectivity. For instance, a large number of studies have shown that increasing task-relevant perceptual load reduces behavioral interference caused by task-irrelevant stimuli and that increasing task-relevant load reduces the neural responses to task-irrelevant information (e.g., Handy \& Mangun, 2000; Lavie, 1995). Modulations in the selectivity of attention that occur with changes in perceptual load can be explained by appealing to the load theory of selective attention (e.g., Lavie, 2005). This theory assumes that the perceptual system automatically and exhaustively devotes all of its available resources to sensory processing. According to this scheme, if the sensory processing demands overload the perceptual system, resources are consumed by task-relevant inputs, resulting in reduced influence of task-irrelevant information (i.e., increased selectivity). If, however, the sensory processing demands do not overload the perceptual system, resources are allocated not only to task-relevant information, but also to task-irrelevant information. Therefore, under conditions of low load, taskirrelevant information has the potential to interfere with behavior and has the potential to evoke neural responses. On the basis of this scheme, we argue that in both experiments reported here, the load manipulation was enough to decrease the availability of perceptual resources or restrict the spatial distribution of attention (Jefferies \& Di Lollo, 2009) in the high T1 load condition relative to the low T1 load condition, and as a result, fewer perceptual resources were available to both process $\mathrm{T} 2$ and spill over to the task-irrelevant distractors. ${ }^{2}$

Appealing to load theory also reconciles the present findings with previous studies showing increased distractor processing during the $\mathrm{AB}$ relative to outside the $\mathrm{AB}$.
Specifically, Jiang and Chun (2001) found that the amount of distractor interference during the $\mathrm{AB}$ was higher than the amount of interference observed outside the $\mathrm{AB}$. Jiang and Chun argued that the typical T1 task taxes capacity-limited later stages of processing that require active control, rather than perceptual stages of processing. Importantly, according to load theory, cognitive control mechanisms play a key role in inhibiting the processing of distractors that have been processed at the perceptual stage. Therefore, if the capacity of the cognitive control processes is exceeded, there is an increased likelihood that task-irrelevant information will interfere with performance. Within the context of the $\mathrm{AB}$, this suggests that if the T1 task does not require all available perceptual resources but is nevertheless cognitively demanding enough to occupy limited-capacity processing mechanisms, processing of task-irrelevant information during the $\mathrm{AB}$ may increase. This increase may occur during the $\mathrm{AB}$ because there are enough perceptual resources available to both process T2 and spill over to the task-irrelevant distractors but not enough postperceptual processing resources to inhibit interference from the task-irrelevant distractors. In contrast, when $\mathrm{T} 2$ is presented outside the $\mathrm{AB}$, enough of the postperceptual processing resources are available to inhibit further processing of task-irrelevant distractors. Consistent with this prediction, in the low T1 load conditions of both experiments, we observed more distractor interference during the $\mathrm{AB}$ than outside the $\mathrm{AB}$.

Although we suggest that the load hypothesis provides a parsimonious account of the present data and also reconciles the present results with previous work, it must be emphasized that we are not suggesting that the $\mathrm{AB}$ is determined solely by perceptual load. Nor are we suggesting that the perceptual resource allocation scheme proposed by load theory is the only manner in which perceptual resources are allocated during the $\mathrm{AB}$. Moreover, we are not proposing that perceptual load is the only factor that serves to reduce perceptual processing during the AB. In contrast, what we are proposing is that, to the extent to which the present manipulations of T1 load affect perceptual-level selection, the present results demonstrate that perceptual load is sufficient to modulate the magnitude of the $A B$ and that perceptual load is sufficient to modulate the extent to which task-irrelevant information is processed during the $\mathrm{AB}$. When the present findings are considered in light of previous work showing that the $\mathrm{AB}$ is modulated by nonperceptual factors (Jolicœur, 1998, 1999; Maki \& Padmanabhan, 1994; Shore, McLaughlin, \& Klein, 2001; Smith, Most, Newsome, \& Zaid, 2006), this suggests that processing during the $\mathrm{AB}$ can be modulated by early-stage perceptual factors, by late-stage central capacity limitations, or by a combination of the two. Furthermore, this supports the notion that the $\mathrm{AB}$ is mediated by multiple stages of information processing (e.g., Dux \& Marois, 2009; Kawahara, Enns, \& Di Lollo, 2006).

\section{Implications}

Since the initial discovery of the AB phenomenon (Broadbent \& Broadbent, 1987; see also Weichselgartner \& Sperling, 1987), over a dozen theoretical accounts 
of the attentional blink have been proposed (for a recent review, see Dux \& Marois, 2009). Despite their variety and their differences in computational specificity, each of these models assume that all stimuli are initially handled by a high-capacity processor that fully identifies information prior to selection and consolidation for report in a manner similar to that proposed by classic late selection models of attention (e.g., Deutsch \& Deutsch, 1963). This common assumption was based on findings that semantic processing was not impaired during the AB (e.g., Vogel et al., 1998) and that high-priority information, such as personal names, survived the AB (Shapiro, Caldwell, \& Sorensen, 1997). As a result, none of the current models can clearly account for the present finding that perceptual load modulates perceptual processing during the $\mathrm{AB}$ or for other recent findings indicating modulations of postperceptual processing during the AB (Giesbrecht et al., 2007; Giesbrecht et al., 2009; Vachon et al., 2007). However, all current models of the AB could be modified to handle the present results if it is assumed that the resources of the initial high-capacity processor are limited. As an initial hypothesis, we propose that these limited perceptual resources are allocated on the basis of the principles of load theory. However, future research is needed to confirm this proposal. Nevertheless, applying load theory in the present context would suggest that if the perceptual load of the $\mathrm{T} 1$ task overloads the initial processing stage, automatic postperceptual processing of T2 would be prevented. If the initial processing stage is not exceeded, postperceptual processing of $\mathrm{T} 2$ would proceed to the extent afforded by the available perceptual resources and by the nature of the T2 stimulus. Importantly, the dynamics of this process would occur independent of the specific functional limitation implicated by each theory of the AB. As a result, the primary implication of the present work with respect to models of the $\mathrm{AB}$ is to more completely specify the models rather than to discriminate between them. More broadly, however, the present results demonstrate not only that perceptual load modulates the distribution of attention in space, but also that perceptual load modulates the distribution of attention in time.

\section{AUTHOR NOTE}

Support for this work was provided by a Yoga Research and Education Foundation grant to B.G. We thank Yaffa Yeshurun, Christian Olivers, and one anonymous reviewer for constructive comments on a previous version of the manuscript. Correspondence concerning this article should be addressed to J. C. Elliott, Department of Psychology, University of California, Santa Barbara, CA 93106 (e-mail: elliott@psych.ucsb.edu).

\section{REFERENCES}

Beck, D. M., \& Lavie, N. (2005). Look here but ignore what you see: Effects of distractors at fixation. Journal of Experimental Psychology: Human Perception \& Performance, 31, 592-607.

Brainard, D. H. (1997). The Psychophysics Toolbox. Spatial Vision, 10, 433-436.

Brehaut, J. C., Enns, J. T., \& Di Lollo, V. (1999). Visual masking plays two roles in the attentional blink. Perception \& Psychophysics, 61, 1436-1448.

Broadbent, D. E., \& Broadbent, M. H. P. (1987). From detection to identification: Response to multiple targets in rapid serial visual presentation. Perception \& Psychophysics, 42, 105-113.
Chun, M. M., \& Potter, M. C. (1995). A two-stage model for multiple target detection in rapid serial visual presentation. Journal of Experimental Psychology: Human Perception \& Performance, 21, 109-127.

de Fockert, J. W., Rees, G., Frith, C. D., \& Lavie, N. (2001). The role of working memory in visual selective attention. Science, 291, 1803-1806.

Dell'Acqua, R., Sessa, P., Jolicceur, P., \& Robitaille, N. (2006). Spatial attention freezes during the attentional blink. Psychophysiology, 43, 394-400.

Deutsch, J. A., \& Deutsch, D. (1963). Attention: Some theoretical considerations. Psychological Review, 70, 80-90.

Dux, P. E., \& MaroIs, R. (2009). The attentional blink: A review of data and theory. Attention, Perception, \& Psychophysics, 71, 1683-1700.

EIMER, M. (1996). The N2pc component as an indicator of attentional selectivity. Electroencephalography \& Clinical Neurophysiology, 99, $225-234$.

Eriksen, B. A., \& Eriksen, C. W. (1974). Effects of noise letters upon the identification of a target letter in a nonsearch task. Perception \& Psychophysics, 16, 143-149.

Giesbrecht, B., Bischof, W. F., \& Kingstone, A. (2003). Visual masking during the attentional blink: Tests of the object substitution hypothesis. Journal of Experimental Psychology: Human Perception \& Performance, 29, 238-255.

Giesbrecht, B., \& Di Lollo, V. (1998). Beyond the attentional blink: Visual masking by object substitution. Journal of Experimental Psychology: Human Perception \& Performance, 24, 1454-1466.

Giesbrecht, B., Sy, J. L., \& Elliott, J. C. (2007). Electrophysiological evidence for both perceptual and postperceptual selection during the attentional blink. Journal of Cognitive Neuroscience, 19, 2005-2018.

Giesbrecht, B., Sy, J. L., \& Lewis, M. K. (2009). Personal names do not always survive the attentional blink: Behavioral evidence for a flexible locus of selection. Vision Research, 49, 1378-1388.

Handy, T. C., \& MANGUN, G. R. (2000). Attention and spatial selection: Electrophysiological evidence for modulation by perceptual load. Perception \& Psychophysics, 62, 175-186.

Handy, T. C., Soltani, M., \& Mangun, G. R. (2001). Perceptual load and visuocortical processing: Event-related potentials reveal sensorylevel selection. Psychological Science, 12, 213-218.

JefFeries, L. N., \& Di Lollo, V. (2009). Linear changes in the spatial extent of the focus of attention across time. Journal of Experimental Psychology: Human Perception \& Performance, 35, 1020-1031.

JiANG, Y., \& CHUN, M. M. (2001). The influence of temporal selection on spatial selection and distractor interference: An attentional blink study. Journal of Experimental Psychology: Human Perception \& Performance, 27, 664-679.

JOLICEEUR, P. (1998). Modulation of the attentional blink by on-line response selection: Evidence from speeded and unspeeded task decisions. Memory \& Cognition, 26, 1014-1032.

Jolicceur, P. (1999). Concurrent response-selection demands modulate the attentional blink. Journal of Experimental Psychology: Human Perception \& Performance, 25, 1097-1113.

Joliceur, P., \& Dell'ACQUA, R. (2000). Selective influence of second target exposure duration and task ${ }_{1}$ load effects in the attentional blink phenomenon. Psychonomic Bulletin \& Review, 7, 472-479.

Joliceeur, P., Sessa, P., Dell'Acqua, R., \& Robitaille, N. (2006a). Attentional control and capture in the attentional blink paradigm: Evidence from human electrophysiology. European Journal of Cognitive Psychology, 18, 560-578.

Joliceur, P., Sessa, P., Dell'Acqua, R., \& Robitaille, N. (2006b). On the control of visual spatial attention: Evidence from human electrophysiology. Psychological Research, 70, 414-424.

KaWAhara, J., EnNs, J. T., \& Di Lollo, V. (2006). The attentional blink is not a unitary phenomenon. Psychology Research, 70, 405-413.

Lavie, N. (1995). Perceptual load as a necessary condition for selective attention. Journal of Experimental Psychology: Human Perception \& Performance, 21, 451-468.

Lavie, N. (2005). Distracted and confused?: Selective attention under load. Trends in Cognitive Sciences, 9, 75-92.

Lavie, N., Hirst, A., De Fockert, J. W., \& Viding, E. (2004). Load theory of selective attention and cognitive control. Journal of Experimental Psychology: General, 133, 339-354.

Lavie, N., \& Tsal, Y. (1994). Perceptual load as a major determinant of 
the locus of selection in visual attention. Perception \& Psychophysics, 36, 183-197.

Loftus, G. R., \& Masson, M. E. J. (1994). Using confidence intervals in within-subject designs. Psychonomic Bulletin \& Review, 1, 476-490.

LuCK, S. J., \& Hillyard, S. A. (1994). Spatial filtering during visual search: Evidence from human electrophysiology. Journal of Experimental Psychology: Human Perception \& Performance, 20, 10001014.

Maki, W. S., \& Padmanabhan, G. (1994). Transient suppression of processing during rapid serial visual presentation: Acquired distinctiveness of probes modulates the attentional blink. Psychonomic Bulletin \& Review, 1, 499-504.

Olivers, C. N. L. (2004). Blink and shrink: The effect of the attentional blink on spatial processing. Journal of Experimental Psychology: Human Perception \& Performance, 30, 613-631.

Olivers, C. N. L., \& Meeter, M. (2008). A boost and bounce theory of temporal attention. Psychological Review, 115, 836-863.

Pashler, H. E. (1998). The psychology of attention. Cambridge, MA: MIT Press.

Raymond, J. E., Shapiro, K. L., \& Arnell, K. M. (1992). Temporary suppression of visual processing in an RSVP task: An attentional blink? Journal of Experimental Psychology: Human Perception \& Performance, 18, 849-860.

Shapiro, K. L., Caldwell, J., \& Sorensen, R. E. (1997). Personal names and the attentional blink: A visual "cocktail party" effect. Journal of Experimental Psychology: Human Perception \& Performance, 23, 504-514.

Shore, D. I., Mclaughlin, E. N., \& Klein, R. M. (2001). Modulation of the attentional blink by differential resource allocation. Canadian Journal of Experimental Psychology, 55, 318-324.

Smith, S. D., Most, S. B., Newsome, L. A., \& ZAID, D. H. (2006). An emotion-induced attentional blink elicited by aversively conditioned stimuli. Emotion, 6, 523-527.

Vachon, F., Tremblay, S., \& Jones, D. M. (2007). Task-set reconfiguration suspends perceptual processing: Evidences from semantic priming during the attentional blink. Journal of Experimental Psychology: Human Perception \& Performance, 33, 330-347.

Vogel, E. K., \& LucK, S. J. (2002). Delayed working memory consolidation during the attentional blink. Psychonomic Bulletin \& Review, 9, 739-743.

Vogel, E. K., Luck, S. J., \& Shapiro, K. L. (1998). Electrophysiological evidence for a postperceptual locus of suppression during the attentional blink. Journal of Experimental Psychology: Human Perception \& Performance, 24, 1656-1674.

Vogel, E. K., Woodman, G. F., \& Luck, S. J. (2005). Pushing around the locus of selection: Evidence for the flexible-selection hypothesis. Journal of Cognitive Neuroscience, 17, 1907-1922.
Weichselgartner, E., \& Sperling, G. (1987). Dynamics of automatic and controlled visual attention. Science, 238, 778-780.

Woodman, G. F., \& LUCK, S. J. (1999). Electrophysiological measurement of rapid shifts of attention during visual search. Nature, $\mathbf{4 0 0}$, 867-869.

YAnTIS, S., \& Johnston, J. C. (1990). On the locus of visual selection: Evidence from focused attention tasks. Journal of Experimental Psychology: Human Perception \& Performance, 16, 135-149.

\section{NOTES}

1. This analysis is directly aimed at testing the hypothesis that T1 load influences the processing of the T2 distractors. However, it is noteworthy that another component in the previously discussed three-way interaction is the constraint that T2 load places on the effect of T1 load. The importance of the constraints that $\mathrm{T} 2$ places on performance during the $\mathrm{AB}$ is perhaps most clearly evidenced in studies in which the T2 display was manipulated (e.g., Brehaut, Enns, \& Di Lollo, 1999; Giesbrecht, Bischof, \& Kingstone, 2003; Giesbrecht \& Di Lollo, 1998; Jolicœur \& Dell'Acqua, 2000; Vogel \& Luck, 2002). On the basis of these previous studies, one might expect that if T2 load is low, the largest determinant of T2 performance will be T1 load; however, if T2 load is high, the constraints put in place by this manipulation are likely to have a larger influence on T2 performance than is T1 load. This aspect of the interaction is different from the hypothesis being tested. The subtraction analysis, on the other hand, isolates the influence of T1 load on the processing of the task-irrelevant distractors, which is a direct test of the prediction.

2. Similarly, it has been found that under certain circumstances, spatial localization is biased toward fixation during the AB (Olivers, 2004). This suggests that during the $\mathrm{AB}$, there is a general mislocalization of spatially presented distractors. Jiang and Chun (2001) proposed a similar notion: that distractor and target locations were confused during the $\mathrm{AB}$. However, Olivers noted that this could be because Jiang and Chun did not include masks on the spatially presented distractors, which could lead to increased saliency. In the present experiments, we avoided this confound by masking the spatial distractors and replicated the previously reported findings in the low $\mathrm{T} 1$ load condition. With regards to the present experiments, an increase in spatial localization toward fixation during the $\mathrm{AB}$ cannot account for the finding that increasing $\mathrm{T} 1$ load decreased the interference effect that distractors had on the T2. If increasing $\mathrm{T} 1$ load increased the bias toward mislocalizing distractors toward fixation, increasing $\mathrm{T} 1$ load should increase interference caused by spatial distractors, which is the opposite of what was observed.

(Manuscript received January 13, 2010; revision accepted for publication June 26, 2010.) 